\title{
Overview on Cucurbita Maxima Seed
}

\author{
Dr. P. Mythili Md ( Siddha ) ${ }^{1}$ Dr. T. Kavitha Md ( Siddha $)^{2}$
}

\begin{abstract}
Pumpkin ( cucurbita maxima) belongs to cucurbitaceae which include pumpkin, gourds, melons and squashes. They are characterized by their seed oil. Pumpkin plant has been grown since the earliest history of mankind ${ }^{I}$. (Brucher-1989 ). Pumpkin are grown around the world for variety of agricultural purposes, the seeds show anti helmintic, taenicide diuretic, cardio tonic, anti-inflammatory, anti - diabetic, antihyperlipidemic, anti - giardial activity CNS stimulant, melanogenesis inhibitory activity and immune modulatory action. Oil from seeds is nervine tonic. Cucurbita maxima seeds are good source of vitamins, minerals, calories and proteins. Multiple forms of phytase found in germinating cotyledons of cucurbita maxima seeds. Seeds are rich in tocopherols ( $\delta$ tocopherols), triterpene and unsaturated fatty acids.
\end{abstract}

Keywords: Tocopherols, phytase, triterpenes, unsaturated fatty acids, anti diabetic, diuretic, cytotoxicity, cardiotonic.

\section{Introduction}

India is a vast repository of medicinal plants that are used in traditional medical treatments but in the last few decades, there has been exponential growth in the field of herbal medicine. It is getting popularized in developing and developed countries owing to its natural origin and lesser side effect ${ }^{2}$. Pumpkin seed oil has a strong anti - oxidant properties and has been recognized for several health benefits such as prevention of growth and reduction of size of bladder and urethral compliance, alleviation of diabetes by promoting hypo glycemic activity, lowering the level of gastric, breast, lung and colorectal cancer.

An early colonist named Elizabeth Skinner found that the seed of pumpkin can be ground into meal and applied to skin, to take away freckles and all spots ${ }^{3}$. Seed have anti-parasitic properties. Oil extracted from the seeds has history of use in biological and folk medicine. Studies indicate that pumpkin seeds provide that wide range of traditional nutrients. The food ranking system qualified them as a very good source of minerals such as $\mathrm{MG}, \mathrm{Mn}, \mathrm{P}, \mathrm{Fe}, \mathrm{Cu}$ and Zinc.

Taxonomy of cucurbita maxima:

$\begin{array}{lll}\text { Division } & : & \text { Spermatophyta } \\ \text { Sub-Division } & : & \text { Angiospermae } \\ \text { Class } & : & \text { Dicotyledonae } \\ \text { Sub-class } & : & \text { Poly patellae } \\ \text { Series } & : & \text { Caliciflorae } \\ \text { Order } & : & \text { Passiflorales } \\ \text { Family } & : & \text { Cucurbitaceae } \\ \text { Genus } & : & \text { Cucurbita } \\ \text { Species } & : & \text { Maximus }\end{array}$

Description of the plant:

Pumpkin plant has large leaves, sprawling veins with coiled, modified leaves called tendrils. The leaves are simple, alternate and shallowly to deeply lobed. The root near the surface, stem would be square, flowers will be bright yellow and the fruit is more fibrous and less sweet than winter squash. Seed vary in size depending upon variety and type ( Fruh Writh \& Hermetter - 2007 ). Pumpkin seed have a natural protective skin called the hull. The pumpkin plant has been grown since the earliest history of mankind ( Brucher - 1989 ). The annual species is probably native to Asia but now nuteralised to temperate and warmer areas.

\section{Chemical constituents of cucrbita maxima seeds:}

Pumpkin seeds are good source of vitamins mostly the B vitamins along with C, D, E, K beside zinc, magnesium, manganese, phosphorous and phytosterol. It contains chemical constituents such as $24 \beta$ ethyl $5 \alpha$

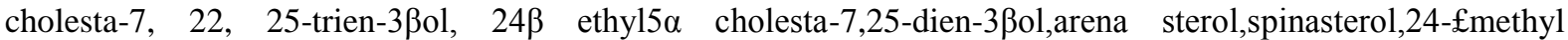
lathosterol and 25(27) dehydro-fungisterol.13 C-NMR of chondrillasterol studied, isolation of new carotenoids cucubitaxanthin( A\&B )and their structure elucidation done. The seeds collected from Pakistan yields an oil (39.1\%)having the following physical chemical constituents, the fatty acid composition of oil is as follow myristic, palmitic, stearic, oleic and linoleic acid 30.3\%.The alcoholic and ethereal extract of seeds were found 
to be active against the nematode fasciolopisbuski in vitro and in vivo test systems .In another study(casio,2000) reported that pumpkin seeds are rich in minerals, calories and proteins, iron, zinc, mg. Seeds contain omega 6 and omega 3 fats and high in fiber. Alfawaz (2004) reported that cucurbita maxima seed kernel contained $39.25 \%$ : crude protein, $27.83 \%$ crude oil, $4.59 \%$ ash and $16.84 \%$ crude fiber together with moderate concentration of $\mathrm{P}, \mathrm{Mg}$ and $\mathrm{K}$. A study on Syrian pumpkin seed oil showed that high content of linoleic acid is important nutritional aspect. Linoleic acid is essential fatty acid for human as it is required for the formation of cellular membranes, Vit D and various harmones (yoshida et,al 2004).

1. A new protein inhibitor of trypsin and activated hageman factor from pumpkin (Cucurbita maxima) seeds : A protein inhibitor (CMTI-V; $M_{\mathrm{r}}$ 7106) of trypsin and activated Hageman factor (Factor $\mathrm{XII}_{\mathrm{a}}$ ), a serine protease involved in blood coagulation, has been isolated for the first time from pumpkin (Cucurbita maxima) seeds by means of trypsin-affinity chromatography and reverse phase high performance liquid chromatography (HPLC ). ${ }^{4}$

2. Isolation and partial amino acid sequence of the trypsin inhibitor from the seeds of Cucurbita maxima : Trypsin inhibitor from squash (Cucurbita maxima) seed was extracted with $0.1 \mathrm{M}$-acetate buffer, $\mathrm{pH} 4.5$, purified on immobilized trypsin, and separated by SE-Sephadex C-50 chromatography into three active fractions. All of them inhibited trypsin to the same extent, showed no antichymotrypsin or antikallikrein activity, had a similar molecular weight (about 3300), and contained no tryptophan, phenylalanine or threonine. The partial amino acid sequence of tryptic and peptic peptides of fraction III was determined by Edman degradation procedure. ${ }^{5}$

3. Codisterol and other $\square^{5}$-sterols in the seeds of Cucurbita maxima : A substantial amount (ca 18\%) of the sterol found in the seeds of Cucurbita maxima had a $\Delta$-bond and consisted of seven components. They were identified as 25(27)-dehydroporiferasterol, clerosterol, isofucosterol, stigmasterol, sitosterol, campesterol and codisterol. ${ }^{6}$

4. Kaurenolide biosynthesis in a cell-free system from Cucurbita maxima seeds : A new product obtained by incubn of $\left[2-{ }^{14} \mathrm{C}\right]$-mevalonic acid with a cell-free system from Cucurbita maxima endosperm was identified by GC-MS as ent-kaura-6,16-dien-19-oic acid, thus in the C. maxima cell-free system, the kaurenolides are formed by a pathway which branches from the GA pathway at ent-kaurenoic acid and proceeds via the dienoic acid.?

5. GC/MS analysis of the plant hormones in seeds of Cucurbita maxima : The GC/MS detection is reported of over 30 compounds, in extracts of the endosperm and embryos from seeds of Cucurbita maxima. The compounds which were identified from reference spectra include: cis, trans- $\mathrm{ABA}$; trans, trans$\mathrm{ABA}$; dihydrophaseic acid; IAA; $\mathrm{GA}_{4} ; \mathrm{GA}_{12} ; \mathrm{GA}_{13} ; \mathrm{GA}_{25} ; \mathrm{GA}_{39}$; $\mathrm{GA}_{43} ; \mathrm{GA}_{49}$; ent-13-hydroxy-, ent- $6 \alpha, 7 \alpha-$ and ent-7 $\alpha, 13$-dihydroxy-, and ent-6 $\alpha, 7 \alpha, 13$-trihydroxykaur-16-en-19-oic acids; ent-7 $\alpha, 16,17$-trihydroxyand ent-6 $\alpha, 7 \alpha, 16,17$-tetrahydroxy-kauran-19-oic acids, ent-6,7-seco-7-oxokauren-6,19-dioic acid and/or ent-6,7-secokauren-6,7,19-trioic acid, and 7 $\beta, 12 \alpha$-dihydroxykaurenolide. ${ }^{8}$

6. Multiple forms of phytase in germinating cotyledons of Cucurbita maxima : Multiple forms of phytase (myoinositol hexaphosphate phosphohydrolase, EC 3.1.3.8) have been isolated in highly purified forms from germinating Cucurbita maxima cotyledons using acetone and ammonium sulphate fractionation, Sephadex gel filtration and ion exchange chromatography on DEAE- and CM-cellulose.'

7. Oil and Tocopherol Content and Composition of Pumpkin Seed Oil in 12 Cultivars: Twelve pumpkin cultivars (Cucurbita maxima D.), cultivated in Iowa,studied for their seed oil content, acid composition and tocopherol content. Oil content ranged from10.9-30.9\%.Total unsaturated fatty acid content ranged from 73.1 to $80.5 \%$.The predominant fatty acids are linoleic, palmitic, oleic and stearic. Significant differences were observed among the cultivars for stearic, oleic, linoleic, and gadoleic acid content of oil. Low linolenic acid levels were observed $(<1 \%)$. The tocopherol content of the oils ranged from 27.1 to $75.1 \mu \mathrm{g} / \mathrm{g}$ of oil for $\alpha$-tocopherol, from 74.9 to $492.8 \mu \mathrm{g} / \mathrm{g}$ for $\gamma$-tocopherol, and from 35.3 to $1109.7 \mu \mathrm{g} / \mathrm{g}$ were studied for their seed oil content, fatty acid composition, and tocopherol content. Oil content ranged from 10.9 to $30.9 \%$. Total unsaturated fatty acid content ranged from 73.1 to $80.5 \%$. The predominant fatty acids present were linoleic, oleic, palmitic, for $\delta$-tocopherol. The study showed potential for pumpkin seed oil from all 12 cultivars to have high oxidative stability that would be suitable for food and industrial applications, as well as high unsaturation and tocopherol content that could potentially improve the nutrition of human diets. ${ }^{10}$

8. Chemical composition and profile characterisation of pumpkin (Cucurbita maxima) seed oil: Gas chromatography revealed that the major fatty acids were oleic, linoleic, and palmitic acids $(44.11 \%$, $34.77 \%$, and $15.97 \%$ respectively). Seed oil was also found to be rich in tocopherols with a predominance of $\delta$-tocopherol (42.27\%). The sterol marker $\beta$-sisosterol accounted for $39.6 \%$ of total sterols contained in seed oil. phenolic acid (protocatechuic, caffeeic, syringic, vanillic, p-coumaric and ferulic were detected. ${ }^{11}$

9. Standarisation Of Etanolic Extract Of C.Maxima Seed: Qualitative analysis showed presence of steroids, carbohydrates, unsaturated and saturated fatty acids in the extract. The RF value of TLC and peak 
of HPTLC showed the presence of various active chemical constituents. The methyl esters were formed and fatty acids were determined using GC-MS techniques. ${ }^{12}$

\section{Medical Uses Of Cucrbita Maxima Seeds (Siddha medicine aspect):}

Action: diuretic, refrigerant, neuronic.

Fried seed taken in night along with sugar and castor oil given in morning kills flat worm (anti helmintic).Seed decoution (16-32gm) act as diuretic and cures leucorrhea. Special oil is extracted from seed.

\section{Pharmacological Activity Of Cucurbita Maxima Seed :}

1. Anti cancer activity: The methanol extract of C.M seed against Ehrlich ascites carcinoma. MECM treatment significantly reduced tumor volume probably by lowering the ascitic fluid volume. The packed cell volume and number of viable EAC tumor cells in peritoneum were significantly lower in mice treated with MECM when compared to tumor control group. Thus it indicate a direct cytotoxic effect of MECM on tumor cells or an indirect local effect, which may involve macrophage activation and vascular permeability inhibition. ${ }^{13}$

2. Anti Obesity: Potentiative activity of cucurbita maxima seed extract with beta vulgaris and smila regelii root extract to reduce extra fat from body. C.M seed sample reach of manganese having tendency to produce thyroxine get potentiate with smilax regelii extract sample iodine reach, produce thyroxine to regulate fat in the body, is additionally benefitted with Beta vulgaris which flush out fat from tissue and blood corpuscles. ${ }^{14}$

3. Diuretic Activity: Diuretic activity of Cucurbita maxima duchense in albino wistar rats. Concentration of $\mathrm{Na}+$ and $\mathrm{K}+$ in urine was determined by flame photometer. The volume of urine, $\mathrm{K}+\mathrm{AND} \mathrm{Na}+$ concentration of test group was compared with control group. The results revealed that the aqeous extract of seeds of cucurbita maxima showed significant increase in urine volume when compared to control group. But the excretion of $\mathrm{Na}+$ and $\mathrm{K}+$ in urine was not significantly increased in drug treated group. Aqeous extract of C.M showed significant diuretic activity. ${ }^{15}$

4. Cardiotonic Activity: Primitive pharmacological screening with crude extract of Cucurbita maxima seeds revealed that it produces inotrophic effect on frog heart and a slight transient rise in mean arterial blood pressure in dog which was not diose dependant. Study of ECG in dog revealed elevation of QRS complex and decrease in heart rate. The extract has beta adrenergic stimulant activity. So C.M shows cardiotonic activity. ${ }^{16}$

5. Human Over Active Urinary Bladder Of Pumpkin Seed Oil: Study evaluated that the effect of pumpkin seed oil on urinary dysfunction in human overactive bladder. Pumpkin seed oil significantly reduced the degree of over active bladder symptoms score. ${ }^{17}$

6. Humoral Immune Response In C.M Seeds : Study evaluated the human immune response in rabbit treated with C.M seeds showed that it has the ability to modulate humoral immune response in normal and immune suppressed rabbits. ${ }^{18}$

7. Protease Inhibitory Of Seed Coat Extract :C.Maxima and citrullus lanata seed coat extract showed good protease inhibitory activity. ${ }^{19}$

8. Anti Inflammatory In Seed Extract -Fore Gut Induced Injury : Results showed CMSE has the ability to maintain fore- gut mucosal intergrity normalizing redox system activity and inflammatory mediators. ${ }^{20}$

9. CNS Stimulant Activity : Study evaluated the CNS stimulant activity of crude drug extract in swiss albino mice, result showed a petroleum ether extract, good CNS stimulant effect that can be explored for therapeutic use as alternative treatment in medical conditions associated with dizziness and sedation. ${ }^{21}$

10. Anti-Giardial Activity: Study showed that C.M petroleum ether extract of seed showed the highest activity against Giardia lambia. The activity due to the presence of triterpene (cucurbitacins). ${ }^{22}$

11. Anti-Helmintic Activity: Study evaluated the antihelmintic activity of C.M using canine tape worm on exposed albino rats. Result showed that anti- helmintic effect at MIC of $23 \mathrm{gr}$ of pumkin seed in 100cc of water. Superficial non erosive gastritis was noted in rats after $4 \mathrm{hrs}$ of $9 \mathrm{gr} / \mathrm{kg} .^{23}$

12. Antidiabetic / Anti Hyperlipidemic: Study evaluated the anti-diabetic and anti-hyperlipidemic effect of various extract of C.M in SIZ induced diabetic wistar albino rats .Results showed significant reduction $(\mathrm{P}<0.05)$ in blood glucose ,LDL, VLDL, triglycerides and marked increase in insulin and HDL cholesterol. ${ }^{24}$

13. Cytotoxicity: In brine shrimp lethality assay, the L50 of methanol extracts and petroleum ether fraction of pumpkin seed were $31.70 \mathrm{ppm}$ and $21.95 \mathrm{ppm}$ respectively. ${ }^{25}$

14. Cytotoxicity And Melanogenesis Inhibition Seeds: Study on seeds yielded 3 new multiflorae type triterpene esters (compound1-3).compound 1 exhibited melanogenesis inhibitory activity .Compound 1-3 showed weak cytotoxicity against HL-60 and P388 cells. ${ }^{26}$ 
15. Antibacterial Activity Of C.M Seed: Ethanol extract of C.M seed showed spectrum inhibition on staphylcoccuds aureus, bacillus subtilis, staphyllo coccus wernerii, pseudomonas putida, pseudomonas aeruginosa, proteus mirabilis, klebsiella pneumonia and e.coli by cylinder plate method. The antibacterial activity of seed extract with different concentration $100-200 \mathrm{mg} / \mathrm{ml}$ was very well compared with standard reference drug Amikacin $25 \mu \mathrm{g} / \mathrm{ml} .^{27}$

16. Toxicity Evaluation Of C. Maxima Seed Extract In Mice: Hydro alcoholic extract of C.M seeds had a considerable safety margin and devoid of acute toxicity.

17. Pumpkin Seed Oil /BPH: Pumpkin seed oil has been approved by the Germany's commission E since 1985 for the treatment of benign prostate hyperplasia.

18. Anti-parasitic activity: Study showed that pumpkin seed can produce anti-helmintic effect. There was alteration in helmintic motility and a protheolithic effect. Egg destruction was noted in the gravid proglottids. ${ }^{28}$

19. Immuno Modulatory Seeds: CM seeds were tested for immune modulatory effects using a dexamethasone induced immune supression model in rabbits. Results showed that C.M possess potential to act as immune modulator. ${ }^{29}$

\section{Conclusion}

Cucurbita maxima seed contain a new protein inhibitor of trypsin and activated hagemann factor (factor $\mathrm{x} 11-\mathrm{A}$ ), codisterol and $\Delta^{5}$ sterols. .Seeds also contain saturated fatty acid (tocopherol10.9-30.90) and unsaturated fatty acid linoleic, palmitic, oleic, stearic(73-80.5\%). Six phenolic acids were detected. Two new carotenoids (Cucrbitacin A\&B) and their structure elucidated. Seeds contain good source of vitamins B, C, D, E $\& \mathrm{~K}$ and minerals like zn , mg ,mn , p. Seeds also contain omega( $3 \& 6)$ and rich in fiber. Seed kernel contains $39.25 \%$ crude protein, crude oil $27.83 \%$, ash $4.59 \%, 16.84 \%$ crude fiber. High oil and protein content make the seed a potential source of commercial vegetable oil. C.M seed has anticancer activity as a direct cytotoxic effect on tumor cell. C.M seed along with some other plant extract act as anti obesity in reducing extra fat from the body. It has diuretic activity in increasing the urine volume. Seed used against BPH. Cucurbita maxima seed has humoral immune response activity. Seed coat has protease inhibitory activity along with citrullus lanatus. Seed has anti-inflammatory activity. Seed oil has CNS stimulant activity associated with dizziness and sedation. Ether extract of seed has anti-giardial activity against Giardia lamblia due to presence of triterpene. Seed has anti--helminthic activity. Seed has anti- diabetic and anti- hyperlipidemic activity by reduction in blood glucose .The triterpene extract of C.M seeds has melanogenesis inhibitory activity, wound healing, anti-scarring and anti-inflammatory properties. Seed has antibacterial activity against certain strains of bacteria. It has immune modulatory effect. Soluble fiber in squash provides a mild laxative effect making it important for digestive health.The seeds are rich in $\delta$ tocopherol which is potent antioxidant and increases the uptake of glucose by muscle thus has anti-diabetic activity. An overview of this article form a new platform in pharmacological and pharmacognostic features and opening a new era for further research on isolation and characterization bioactive compounds and evaluation of new therapeutic activity.

\section{References:}

[1]. Verma, Sheethal et, al current and future status of herbal medicine. Veterinary world2008; 1:347_350.

[2]. Brahmachari, U.N herbal drugs. Current science2001; 81:15-16.

[3]. Doi; 10,3390/molecules 19044802

[4]. A new protein inhibitor OF trypsin and activated Hageman factor from cucurbita maxima seeds. Department Of Biochemistry,Kansas State University, Manhattan, ks66506, USA. Department of biological science, University of Durham, UK.

[5]. Isolation of partial amino acid sequence of the trypsin inhibitor from the seeds of cucurbita maxima. Acta biochimica polanica (1980,27(3-4):371-382.Journal article, Research support, Non -US, govt.

[6]. VIPIN k , Garg, Williiam R Neas, Department of biological science, Drexel university Philadelphia,PA 19104,USA.Codisterol and other $\Delta 5$-sterols in the seeds of cucurbita maxima. 7.Peter Hedden, Jan E Graebe, pflanzenphysiologisches institute, Untere karspule2,3400 Gottingen ,West Germany. Kauernolide biosynthesis in a cell-free system from cucrbita maxima seeds.

[7]. A.R.C Research unit, school of chemistry, the university ,Bristol BS81TS,UK.pflanzen physiologisches institute Untere karspule 2,3400 Gottingen,F.R.G.

[8]. Meera Goel ,C.B Sharma.Post graduate department of chemistry ,Biochemical laboratories, D.A.V college ,Meerut University, Muzaffar nagar 251002,(u.p),India.

[9]. David G Steven son ,Fred J Eller,Liping Wang, Jay-lin Jane, Tong Wang and George Einglett. Cereal product of food science research unit and new crops research unit ,National centre for agriculture utilization research, agriculture research service U.S .Department of agriculture,1815 ,North university street ,Peoria,Illinois61604 and department of food science and human nutrition,2312 food science building, Lowa state university. Oil and tocopherol content and composition of pumpkin seed oil

[10]. Leila Rezig,Monocef Chouaibi,Kamel Msadda,Salem Hamidi volume 37 issue-1,may 2012. Chemical composition and profile charecterisation of pumpkin seed oil.

[11]. Richa bajpai, Nidhi Jain A.K Pathak, Journal of applied pharmaceutical science 02(08);2012:92-95. Anticancer extract of methanol extract of cucurbita maxima against Ehrlich ascites carcinoma .Int.J.rRes,pharm.Sci2011;1:52-59. 
[12]. Das,R.et al. potentiative activity of cucurbita seed extract with beta vulgaris and smilax Regelli root extract to reduce extra fats from the body. International journal of pharmaceutical science and research 2010;1:57-62.

[13]. Jose, M.A.et al .Diuretic activity of seeds of cucurbita maximus duchense in albino wistar rats .Indian J pharmacol 2008;40:

[14]. Lahon L.C.et al preliminary pharmacological and anti cestodal screening of cucurbita maxima, Ind.J.IJJP VOL2 ISSUE3.

[15]. Pumpkin seed oil extracted from cucurbita maximaimproves urinary disorder in humans over active bladder /Mic Nishimura.Tatsuya, Ohkawarw, Hiroji sato, Hiroshi Tajkeda,Jun nishihira/Journal of traditional and complementary medicine,2014;4(1):72-74/DOI:10.4103/2225-4410.124355.

[16]. Estimation in humoral response in rabbits fed with cucrbita maxima seeds/V.Ranganathan,S.Selva Subramanian,and S.Vasantha kumar/Vet world 6(7):396-399/doi :10.5455/vet world,2013;396-399.

[17]. Protease inhibition studies and metallic responses oof cucurbita maximus and citrullus lanatus seed coat extracts/Mr.Sreenu Barla,Dr.DSVGK Kaladhar,DrGovindha Roa Duddukkuri/IJSR-INTERNATIONAL JOURNAL OF SCIENTIFIC RESEARCH,sept 2013;2(9).

[18]. Anti inflammatory effect of cucurbita maxima sweet seed extract on foregut induced injury; role of oxidative stress/IrenapshykTitko and Oskana Zayachikvska/The FASEB JOURNAL.

[19]. Central nervous stimulant effect of the oils obtained from seed of cucurbita maxima/Dpke P.P TareH.L, SherikarAK, ShendeV.S,Deore S.R DamaG.Y/Journal of pharmaceutical biology,2011;1(1):30-36.

[20]. Anti giardial activity of some species of cucurbita and LageneriaSiceraria / Mahmoud M.DDahab, Yahia Mohammed EI Imam, MONA Abdu Elmonem Abdu El Magged/Journal of forest products and industries,2013;2(4)43-47.

[21]. Preclinical studies of cucrbita maxima , a traditional intestinal parasitic in rural urban areas/Diaz Obregon D,Lioja LOZANO 1,Carbajal Zuninga V./Rev gastro enteral Peru, oct-dec,2004;24(4)323-7.

[22]. Anti diabetic and Anti hyperlipidemic activity of cucrbita maxima Duchense seeds of Streptozotocin induced diabetic rats/Ashok Sharma, Tara chand,Manoj KHARDIYA, kailash chand yadav/Journal of pharmacognosy and phytochemistry,1(6).

[23]. Cytotoxicity and phyto chemical studies of pumpkin seed extract/Matihar Rahman /Journal of biomedical and phytochemical research, 2014;3(2)

[24]. Three new triterpene esters of pumpkin seeds /Takashi kikuchi, Shinsuke Ueda, Jokaku kanazawa, Hiroki Naoe, Takeshi Yamada and Reiko Tanaka/molecules 2014;19:4802-4813 doi:10.3390/ molecules 19022802.

[25]. Preliminary phyto chewmical screening and in-vitro anti bacterial activity of cucurbita maxima seed extract, K.Ravishankar, GVN.Kiran mayi,GV.Appa reddy, VVL. Sowjana, V.Baba sainadh,VG.Lakshmi durga, V.Sivaprasad, PV.Swami naidu and T.Prasad. INTERNAL JOURNAL OF RESEARCH IN PHARMACY AND CHEMISTRY,IJRPC2012,2(1) ISSN:2231-2781.

[26]. Toxicity evaluation of cucurbita maxima seed extract in mice /Summary pharmaceutical biology/2006; 44(4):301-303.

[27]. Comparative effect of cucurbita maxima seed with immune modulators on biochemical parameters in rabbits/V.Ranganathan and S.Selvasubramanian /Journal of applied pharmaceutical science, 2012; 02(06):191-193. 